Available Online at https://www.nepjol.info/index.php/IJOSH,

International Journal of Occupational Safety and Health, Vol. 6 No. 2 (2016) 1 - 5

\title{
Hearing Loss among the Traffic Police in Kathmandu Valley - Finding from a Pilot Cross-Sectional Study
}

Madhab Raj Bista'; Pranab Dahal ${ }^{2}$

${ }^{1}$ Madhab Raj Bista, Occupational Safety and Health Project (OSHP), Bhainshepati, Kathmandu, Nepal ${ }^{2}$ Pranab Dahal, ECO Trans Consult, Kathmandu, Nepal

\section{ABSTRACT}

Background: Noise induced hearing loss has been increasing rapidly with the advancement of technological, industrial and anthropogenic growth. Hearing loss is identified to be minimizing psychosocial well-being of an individual and reduced economic activities apart from deafness. This study aimed to measure the noise induced health impairment in traffic polices of Kathmandu valley.

Methods and Materials: The cross-study was conducted among eighty traffic police in the Kathmandu and Lalitpur districts of Nepal. Purposive stratified sampling method was used for the study. A semi structured interview guide was developed to assess the physical findings and an audiometric test were also conducted with each individual traffic personnel to assess the hearing impairment.

Results: The study identified Chabahil in Kathmandu with highest level of noise at $90 \mathrm{~A}$-weighted decibel. Overall, moderate hearing loss in the left ear was reported in $55 \%$ of the respondents and mild hearing list in right ear in $46.3 \%$ of the respondents. The study found bilateral moderate hearing loss in all the respondent serving more than twenty years in traffic management. The effects of getting tired (80\%), difficulties in concentration $(76.3 \%)$ and increased irritation (72\%) were identified as the high ranked health effects

Conclusion: The study reinforces the need of further exploration as this occupational health issue is a growing public health concern.

Key words: Exposure, health effects, noise, service years, traffic police

DOI: https://doi.org/10.3126/ijosh.v6i2.22525

\section{Introduction}

$\mathrm{N}$ oise induced hearing loss has been increasing rapidly with the advancement of technological, industrial and anthropogenic growth, and the constant exposure to the hazardous noise level can result to adverse consequences for the affected population. The disability caused due to occupational hearing loss are identified to be preventable [1]. The data gap on the exposure to the noise in the developing nations are limited, but the evidences from developed nations infers that the average occupational noise levels are beyond the permissible limits [2,3]. Apart from the direct outcome deafness, noise induced hearing loss are also attributed to decreased psychosocial wellbeing, psychiatric disorders and effects on performance amongst the affected population [4]. The

\section{Corresponding Author}

Madhab Raj Bista, Occupational Safety and Health Project (OSHP), Bhainshepati, Kathmandu

E-mail: bista.darchula@gmail.com

(c) 2016 IJOSH All rights reserved pathophysiology for the hearing impairment is due to the impact of the noise to the delicate inner ear leading to the death of cell in the basilar membrane of the cochlea [5]. The consequences of hearing loss reduce individual ability to interpret sound, economic and educational disadvantage, isolation and also stigmatization [6]. Two earlier studies from Kathmandu had identified that the noise level has been increasing reaching to $80 \mathrm{~A}$-weighted decibel (dBA) and the study has also categorized different places in Kathmandu as high, moderate and low levels based on the locations and traffic movement $[7,8]$. The occupational hearing loss results from the continuous exposure to the noise for the longer duration and among this population, the traffic police with constant exposure to the noise are at particular risk. This study aimed to measure the noise induced health impairment in traffic polices of Kathmandu valley.

\section{Method and Materials}

The study was conducted among eighty traffic 
police personnels in Kalanki, Jawalkhel, Satdobato, Koteshwor, Maharajgunj, Balaju and Gaushala area of Kathmandu and Lalitpur district during the month of January 2010. This cross sectional study used purposive stratified sampling method. A semi structured interview guide was developed to assess the physical findings and an audiometric test were also conducted with each individual traffic personnel to assess the hearing impairment.

The health effects due to constant exposure to noise consisted of eleven different questions. The question consisted a ranking scale where the respondents selected the health effects to the scale No, Negligible, Low, Medium and High.

Informed consent was taken from each respondent and confidentiality was maintained. All the data were tabulated with various types of singular or cross tabulation was prepared to analyze the data. Necessary Charts were used to summarize the data.

\section{Result}

\section{Respondent background}

The study was conducted among eighty traffic police out of which $93.8 \%$ were male and $6.2 \%$ were female. The age group of majority of respondents fell in the categories of 20-29 years' age bracket. Most of the interviewed respondents had a service year of below fifteen years and close to nine percent of respondents having a service period of beyond fifteen years. A close to fourteen percent and forty-two percent of respondents admitted of smoking and drinking habits respectively. The highest number of samples were taken from Koteshwor $(20 \%)$ with least from Satdobato $(8.8 \%)$. The table 1 below shows the general background of the respondent and the sample location.

\section{Noise levels}

Noise level measurement was done at all traffic post at the various time intervals. The highest noise level was monitored to $90 \mathrm{dBA}$ at Chabahil station at 9:00 in the morning about. Similarly, the second highest sound level was measured at Koteshowr and Kalanki station at the range of $85 \mathrm{dBA}$ during 16:00. The noise level of around $80 \mathrm{dBA}$ during 16:00 was found at Chabahil, Satdobato, Gausala, Balaju and Maharajgunj station respectively. It was identified that the noise level remained same at around $80 \mathrm{dBA}$ during 13:00 at all the stations respectively. The details of the measured noise levels at the various stations at the given time is shows in the figure 1 below.

\section{Experience on Health Effects}

The effects of getting tired $(80 \%)$, difficulties in concentration $(76.3 \%)$ and increased irritation $(72 \%)$ were identified as the high ranked health effects.

Table 1: General background of the respondent (percent \%)

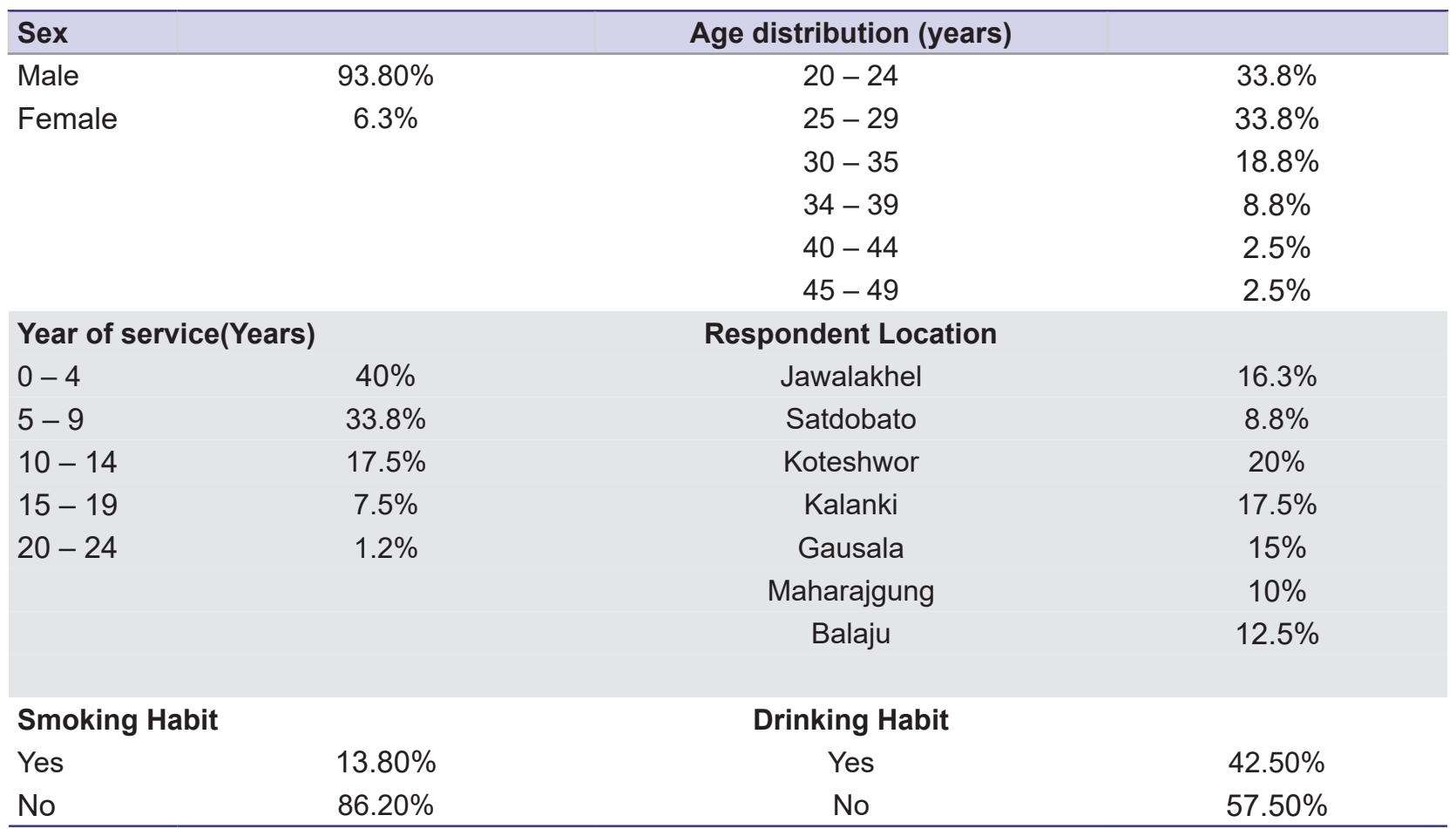


The details of the health effects identified by the respondents has been listed in the table 2 below.

\section{Degree of hearing loss}

The hearing loss of both mild and moderate categories were identified during the observation, both ears of the traffic police were found to be affected. Moderate hearing loss in the left ear was reported by 55 percent of the respondents while 46.3 percent reported of mild hearing loss in the right ear. As per the study, only $2.5 \%$ of the right ear and 6.3 percent of the left ear of the respondents were found to be normal.

The data suggested noise level of $77.75 \mathrm{dBA}$ at the surrounding area of Jawalakhel where hearing loss on right ear was 38.5 percent and left ear was 38.5 percent in mild hearing loss category, whereas in moderate hearing loss category, hearing loss were 53.8 percent on right ear and 61.5 percent in left ear. The table 3 below shows the relation between location, hearing loss and the noise level at various monitoring stations.

The service period for the traffic police personnel ranged from months to beyond 20 years of service. The 0-4 years of service period identified the mild hearing loss in the right ear among 53.1 percent of the respondents and moderate hearing in about sixty percent of the respondents. Hundred percent of the respondents with more than 20 years of service reported to have moderate hearing loss in bilateral ears (Table 4).

Table 2: Experience on Health Effects

\begin{tabular}{lccccc}
\hline Health Effect & No & Negligible & Low & Medium & High \\
\hline Could not hear properly until other speaks loudly & $41.30 \%$ & $1.30 \%$ & $8.80 \%$ & $18.80 \%$ & $30 \%$ \\
\hline Get tired often working in the noisy area & $1.30 \%$ & 0 & $1.30 \%$ & $17.50 \%$ & $80 \%$ \\
\hline Irritation(increase in temper/aggressive) & $5 \%$ & $1.30 \%$ & $6.30 \%$ & $15 \%$ & $72 \%$ \\
\hline Headache & $26.30 \%$ & 0 & $17.50 \%$ & $38.80 \%$ & $17.50 \%$ \\
\hline Speech disturbance & $90 \%$ & 0 & $3.80 \%$ & $2.50 \%$ & $3.70 \%$ \\
\hline Sleep disturbance & $87.50 \%$ & 0 & $7.50 \%$ & $2.50 \%$ & $2.50 \%$ \\
Chest pain & $56.20 \%$ & 0 & $6.30 \%$ & $30 \%$ & $7.50 \%$ \\
\hline Feeling of vomiting & $86.30 \%$ & $2.50 \%$ & $7.50 \%$ & $3.70 \%$ & 0 \\
Dizziness & $57.50 \%$ & $2.50 \%$ & $10 \%$ & $27.50 \%$ & $2.50 \%$ \\
\hline Difficulties in concentration & $7.50 \%$ & 0 & $10 \%$ & $6.30 \%$ & $76.30 \%$ \\
\hline Ringing of ear & $11.30 \%$ & $1.30 \%$ & 0 & $22.50 \%$ & $65 \%$ \\
\hline
\end{tabular}

Table 3: Location verses hearing loss and noise level

\begin{tabular}{lccccccc}
\hline \multirow{2}{*}{ Location } & \multicolumn{2}{c}{ Mild } & \multicolumn{2}{c}{ Moderate } & \multicolumn{2}{c}{ Normal } & \multirow{2}{*}{ Mean dBA level } \\
\cline { 2 - 6 } & Right ear & Left ear & Right ear & Left ear & Right ear & Left ear & \\
\hline Jawalakhel & $38.5 \%$ & $38.5 \%$ & $53.8 \%$ & $61.5 \%$ & $7.7 \%$ & & 77.75 \\
Satdobato & $42.9 \%$ & $28.6 \%$ & $57.1 \%$ & $71.4 \%$ & & & 78.31 \\
Koteshwor & $18.8 \%$ & $12.5 \%$ & $81.3 \%$ & $87.5 \%$ & & & 82.37 \\
\hline Kalanki & $64.3 \%$ & $50.0 \%$ & $35.7 \%$ & $21.4 \%$ & & $28.6 \%$ & 81.93 \\
Gausala & $66.7 \%$ & $33.3 \%$ & $33.3 \%$ & $66.7 \%$ & & & 78.37 \\
Maharajgung & $75.0 \%$ & $62.5 \%$ & $25.0 \%$ & $37.5 \%$ & & & 80.37 \\
Balaju & $30.0 \%$ & $60.0 \%$ & $60.0 \%$ & $30.0 \%$ & $10.0 \%$ & $10.0 \%$ & 80.43 \\
\hline Total & $\mathbf{4 6 . 3 \%}$ & $\mathbf{3 8 . 8} \%$ & $\mathbf{5 1 . 3} \%$ & $\mathbf{5 5 . 0} \%$ & $\mathbf{2 . 5} \%$ & $\mathbf{6 . 3} \%$ & \\
\hline
\end{tabular}

Table 4: Years of service verses hearing loss

\begin{tabular}{ccccccc}
\hline \multirow{2}{*}{ Year of Services } & \multicolumn{2}{c}{ Mild } & \multicolumn{2}{c}{ Moderate } & \multicolumn{2}{c}{ Normal } \\
\cline { 2 - 7 } & Right ear & Left ear & Right ear & Left ear & Right ear & Left ear \\
\hline $0-4$ & $53.1 \%$ & $28.1 \%$ & $43.8 \%$ & $59.4 \%$ & $3.1 \%$ & $12.5 \%$ \\
$5-9$ & $33.3 \%$ & $44.4 \%$ & $63.0 \%$ & $51.9 \%$ & $3.7 \%$ & $3.7 \%$ \\
$10-14$ & $64.3 \%$ & $57.1 \%$ & $35.7 \%$ & $42.9 \%$ & $0.0 \%$ & 0 \\
$15-20$ & $33.3 \%$ & $33.3 \%$ & $66.7 \%$ & $66.7 \%$ & $0.0 \%$ & 0 \\
$20-24$ & $0.0 \%$ & $0.0 \%$ & $100.0 \%$ & $100.0 \%$ & 0 & 0 \\
Total & $\mathbf{4 6 . 3} \%$ & $\mathbf{3 8 . 8} \%$ & $\mathbf{5 1 . 3} \%$ & $\mathbf{5 5 . 0} \%$ & $\mathbf{2 . 5 \%}$ & $\mathbf{6 . 3} \%$ \\
\hline
\end{tabular}




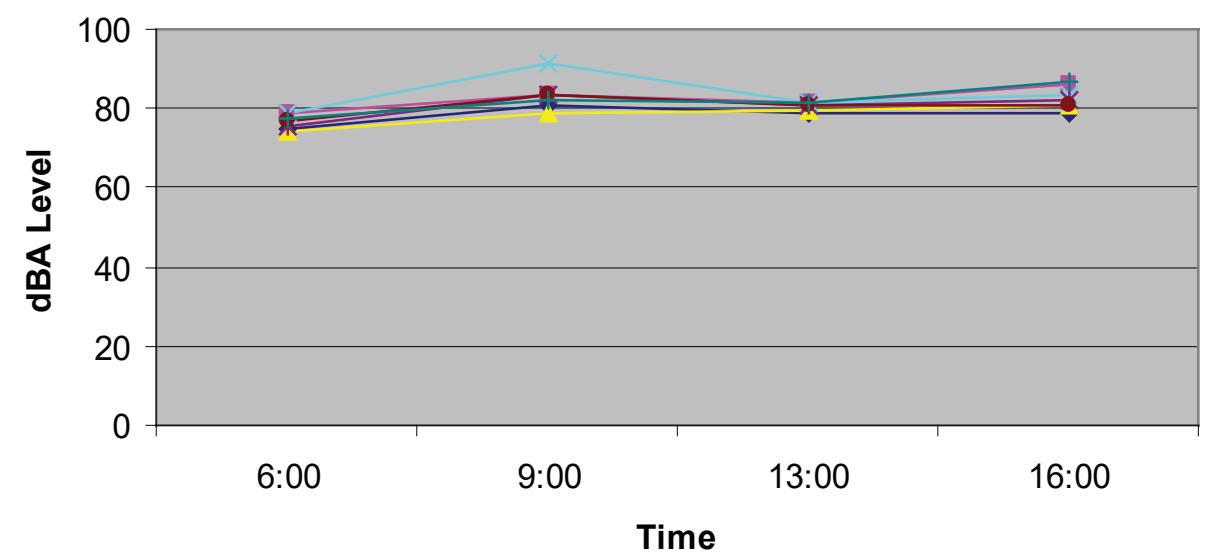

$$
\begin{aligned}
& \longrightarrow \text { Satdobato } \longrightarrow \text { Koteshowr } \longrightarrow \text { Gausala } \rightarrow \text { Chahabil } \\
& \rightarrow \text { Maharajgung } \longrightarrow \text { Balaju } \longrightarrow \text { Kalanki }
\end{aligned}
$$

Figure 1: Measured noise level at different locations and time

\section{Discussion}

Hearing loss resulting from any occupation leads to multitudes of personal health effects and social cost associated with the disability. The irreversible nature of impact on the hearing loss is also attributed to be the greatest risk factor for the exposed population. The study found sound level double the threshold of $41 \mathrm{dBA}$ set by the World Health Organization exceeds in some of the monitoring stations. In this study, traffic police with longer duration of service were at highest risk of developing bilateral hearing loss. The observed hearing loss can be attributed to prolonged exposure to the road traffic noise leading to constant and permanent negative impact in the inner ear hair cells and subsequent failure in initiating any impulse [9].

Around the globe, occupational noise exposure contributes to approximately $7 \%$ to total deafness rates in the most developed nations and $21 \%$ in developing countries[10]. According to our study, moderate hearing loss in the left ear was reported by 55 percent of the respondents while 46.3 percent reported of mild hearing loss in the right ear. These findings were however quite different than the finding from other studies, where the prevalence of hearing loss was found to be $28 \%$ in
French police officer, $81.2 \%$ in traffic police of Pune, India and $84 \%$ in traffic police in Jalgaon Urban Centre of India [11].

Similarly, as per our study, all the traffic police personnel serving more than 20 years in the field was diagnosed with bilateral moderate hearing loss. As per study done in Bangladesh, $24 \%$ of the traffic policeman of Dhaka had mild to moderate sensorineural hearing loss due to noise exposure and the findings were directly related to duration of exposure [12].

Despite of being identified as a major factor for hearing loss, noise control measures and use of protectors are seldom use in most of the cases other than heavy machine operators.

The gravity of this public health concern requires further exploration as more people are at high risk equally exposed by virtue of living in the areas adjacent to noise sources.

\section{Conclusion}

Traffic person exposed to constant high intensity sound are at high risk of developing hearing loss. Concerned authorities need to work on this issue for minimizing the associated risk.

\section{References}

1. Rabinowitz P. Noise-induced hearing loss. American Family Physician. 2000;61(9):2759- 60.

2. Suter A. Standards and regulations. In: Berger EH, Royster LH, Rozster JD, Driscoll DP, Layne M, eds.

The noise manual. 5th ed. Fairfax VA: American Industrial Hygiene Association; 2000.

3. Goelzer B, Hansen $\mathrm{CH}$, Sehrndt GA, eds. Occupational exposure to noise: evaluation, prevention and control. Geneva, Berlin: World Health 
Organization, Federal Institute for Occupational Safety and Health; 2001.

4. Hollander A, Kempen E, Houthuijs D, Kamp I, Hoogenveen R, Staatsen B. Environmental noise: an approach for estimating health impacts at national and local level. Geneva: World Health Organization; 2004.

5. Glorig A, Dixon W, James N. Damage Risk Criteria and Noise-Induced Hearing Loss. Archives of Otolaryngology—Head \& Neck Surgery. 1961;74(4). DOI: https://doi.org/10.1001/ archotol.1961.00740030422010

6. Mathers C, Smith A, Concha M. Global burden of hearing loss in the year 2000. Geneva: World Health Organization; 2000. Available from: https://www. who.int/healthinfo/statistics/bod_hearingloss.pdf

7. Sapkota B. A study of Community Noise in Kathmandu valley. A report submitted to the Nepal Academy of Science and Technology, Kathmandu, Nepal; 1997.
8. Kadel H, Regrni S, Pradhananga T. Noise Level Monitoring in Kathmandu Valley Nepal Journal of Science and Technology. 2003;5(1):115-20.

9. Nandi S, Dhatrak S. Occupational Noise Induced Hearing Loss in India. Indian Journal of Occupational and Environmental Medicine. 2008;12(2):53-6. DOI: https://doi.org/10.4103/0019-5278.43260

10. Thorne PR, Ameratunga, Stewart J, Reid N, Williams W, Purdy SC, Dodd G and Wallaart J. Epidemiology of noise induced hearing loss in New Zealand. J NZ Med Assoc. 2008;121:1280.

11. Nelson DI, Nelson RY, Concha-Barrientos $M$, Fingerhut $M$. The global burden of occupational noise-induced hearing loss. Am J Intern Med. 2005;48:pp.1-15. DOI: https://doi.org/10.1002/ ajim. 20223

12. Sharif A, Taous A, Siddiqui $B H$ and Dutta PG. Prevalence of noise induced hearing loss among traffic police in Dhaka Metropolitan City. Mymensingh Med J 2009;18(1):24-28 